\title{
Temperamento: Características e Determinação Genética
}

\author{
Patricia do Carmo Pereira Ito ${ }^{12}$ \\ Raquel Souza Lobo Guzzo \\ Pontifícia Universidade Católica de Campinas
}

\begin{abstract}
Resumo
Este estudo investigou características temperamentais de uma amostra de crianças de 7 a 14 anos, verificando inclusive a influência exercida pela genética na determinação do temperamento. Uma amostra de 26 pais forneceu dados sobre o temperamento de 26 pares de gêmeos (15 monozigóticos, 11 dizigóticos), os quais totalizavam 52 sujeitos. Para coleta de dados foi utilizada a Escala Pavlovian Temperament Survey, versão infantil, que investiga três fatores de temperamento: Força de Excitação (FE), Força de Inibição (FI) e Mobilidade (MO). Resultados obtidos indicaram que a partir da percepção dos pais, esta amostra de sujeitos possuía como característica predominante de temperamento a mobilidade. Análise de variância (MANOVA) indicou que as características temperamentais variavam quando consideradas as variáveis sexo e faixa etária. Considerando-se a gemealidade, correlações obtidas entre pares de gêmeos monozigóticos e dizigóticos evidenciaram a influência exercida pela genética na determinação dos três fatores de temperamento.

Palauras-chave: Temperamento; gêmeos; crianças.
\end{abstract}

Temperament: Characteristics and Genetic Determination

\begin{abstract}
This study investigated the temperament characteristics of a sample of children from 7 to 14 years old, verifying the influence of genetics in the determination of temperament. A sample of 26 parents provided data about temperament of 26 pairs of twins (15 monozigotic, 11 dizigotic), totalizing 52 subjects. For the data gathering, the Pavlovian Temperament Survey - PTS, child version was used, which investigates three temperament factors: Strength of Excitation (SE), Strength of Inhibition (SI) and Mobility (MO). The results showed that, from parents' perception, this sample had mobility as the predominant temperament characteristic. Analysis of variance (MANOVA) indicated that temperament characteristics varied when considering variables such as sex and age group. The correlation obtained from pairs of monozigotic and dizigotic twins made evident the influence of genetic determination on the three factors.

Keywords: Temperament; twins; children.
\end{abstract}

As questões referentes às diferenças individuais têm sido uma preocupação constante na busca do conhecimento psicológico e têm acompanhado o homem ao longo de sua história. Diferentes dimensões, traços ou características são identificadas, dependendo do autor, do enfoque teórico e do período em que ocorreram os estudos. Cientistas, principalmente psicólogos, buscam conhecer como as características cognitivas e de personalidade variam entre indivíduos e grupos.

Entre as características individuais estudadas, ênfase especial tem sido dada às características de personalidade, mais especificamente ao temperamento. Este constructo vem sendo amplamente pesquisado, principalmente na Europa

\footnotetext{
${ }^{1}$ Endereço para Correspondência: Rua dos Guatás no 250, 12B, 13081-060. Campinas, SP. E-mail: paty_ito@directnet.com.br

${ }^{2} \mathrm{O}$ presente estudo faz parte da dissertação de Mestrado em Psicologia Escolar da primeira autora realizada sob orientação da segunda autora. Agradecemos a colaboração de Cristina C.M. Pinho, Mônica Gobitta, Carolina F.C. Carvalho, Nilza Catini, Ana Carolina G. Gayotto, Cristiane M.M. Valle, Maíra P.C. Silva Raquel Tizzei e Tatiana Gazzell integrantes do Laboratório de Avaliação e Medidas Psicológicas - LAMP da PUC Campinas, durante a coleta de dados e o apoio financeiro do CNPq.
}

e nos Estados Unidos, onde grandes esforços têm sido despendidos em sua avaliação, sua relação com outros constructos e sua aplicabilidade na área clínica e escolar.

Estudado por diferentes autores, como por exemplo, Gerard Heymans (Strelau, 1994, 1998), Ivan Pavlov (Strelau, 1997, 1998; Strelau, Angleitner \& Newberry, 1999), Eysenck (Boeree, 1998, Strelau, 1998), Thomas e Chess (Chess \& Thomas, 1987), Goldsmith e colaboradores (Goldsmith \& cols., 1987), Buss e Plomin (Buss, 1995), Rothbart (1986a, 1986b), Windle e Lerner (1984) e Strelau (1991, 1994, 1998), entre outros, o temperamento apresenta diferenças teóricas. Essas diferenças estão relacionadas à: 1) número diferenciado de dimensões do temperamento; 2) diferentes ênfases dadas ao fator biológico; 3) função da motivação no temperamento; 4) definições de temperamento, que em alguns casos dizem respeito ao aspecto comportamental, mas em outros se referem ao aspecto psicofisiológico; 5) alguns teóricos enfatizam a regulação e o controle de componentes do comportamento como aspecto do temperamento, enquanto outros se referem a estilos de comportamento; 6) diferentes concepções relacionadas às influências do contexto e das relações interpessoais no 
temperamento; e, 7) diferentes limites estabelecidos entre personalidade e temperamento (Goldsmith \& RieserDanner, 1986). As diferentes concepções sobre a definição do temperamento e suas dimensões conduzem os pesquisadores a utilizarem diferentes instrumentos e métodos (observação, entrevista, escalas, questionários, procedimentos experimentais de medidas fisiológicas e psicofisiológicas) os quais variam em função da abordagem teórica utilizada (Ito \& Guzzo, 2002).

Um fato constatado é o de que apesar das diferenças, os teóricos concordam que o temperamento: 1) referese a dimensões gerais de comportamento representando padrões universais de desenvolvimento; 2) manifesta-se já durante a infância e constitui biologicamente a personalidade; 3) é relativamente estável ao longo do tempo; 4) apresenta substrato biológico; 5) fatores do contexto podem influenciar as expressões temperamentais (Goldsmith \& Rieser-Danner, 1986).

Entre as características citadas acima, destaque especial é dado ao substrato biológico, considerado aspecto importante para definição e delimitação do constructo, bem como presente, em maior ou menor grau, em todos enfoques teóricos sobre temperamento. $\mathrm{O}$ substrato biológico do temperamento pode ser expresso de diferentes maneiras como, por exemplo, referindo-se a mecanismos anatomo-fisiológicos, fatores bioquímicos, hereditariedade do temperamento, entre outros.

Como comprovar o substrato biológico do temperamento? Strelau $(1994,1998)$ considera que a sustentação das bases biológicas do temperamento decorre de: a) estudos genéticos comportamentais, b) estudos da infância neonatal, e c) pesquisas demonstrando variáveis fisiológicas e bioquímicas mediando características temperamentais (no homem e em outras espécies de mamíferos). Segundo Strelau e Angleitner (1991), a origem biológica do temperamento pode ser sustentada devido ao fato de que as características temperamentais podem ser observadas desde as primeiras semanas de vida, e que diferenças de temperamento têm origem genética. Porém conforme afirma Bates (1989), é importante ressaltar que aceitar a influência genética não significa partir do princípio de que o código genético programe o traço completamente, mas, sim, que os padrões genéticos determinam as respostas iniciais.

A influência exercida pela genética na determinação do temperamento é investigada principalmente por meio de estudos de genética comportamental, os quais consideram que os genes são responsáveis por traços ou comportamentos. É importante frisar porém que os genes não agem diretamente sobre o comportamento, eles afetam dimensões das diferenças individuais pela modificação de estruturas biológicas, regulação de processos em andamento, codificação de proteínas que afetam estruturas e processos regulativos. Pesquisadores, biologicamente embasados, têm procurado identificar estruturas particulares, caminhos neurais, transmissores químicos, ou hormônios, associados às diferenças individuais (Revelle, 1995). Para Strelau (1998), os genes interagem na determinação das diferenças individuais, e a transmissão genética está associada à variabilidade genética nos mecanismos fisiológicos e bioquímicos subjacentes aos traços de temperamento.

As pesquisas em genética comportamental estão interessadas em investigar a influência de fatores genéticos e ambientais (Plomin \& Rende, 1991) e em explorar a origem das diferenças individuais no funcionamento psicológico e comportamento (Baker \& Clark, 1990). Seus métodos de estudo estão baseados na hipótese de que se diferenças individuais no comportamento ou traço têm determinação genética, similaridades em traços ou comportamentos podem ocorrer devido à similaridade de genes (grau de parentesco). Isto significa que quanto mais genes são compartilhados pelos indivíduos, mais similares eles podem ser com respeito ao traço ou comportamento que tem origem genética. De acordo com a teoria poligenética, pais e filhos e também irmãos (fraternos e gêmeos dizigóticos) compartilham em média $50 \%$ de seus genes; gêmeos monozigóticos compartilham $100 \%$, avós e netos $25 \%$ e primos de primeiro grau 12,5\% dos genes (Strelau, 1998).

Os geneticistas comportamentais examinam a arquitetura genética de traços específicos, assim como variações entre traços, e destes com diferentes fatores do ambiente (Revelle, 1995). Eles observam as variações que ocorrem nos traços, entre pessoas que estão relacionadas geneticamente de diferentes maneiras, e determinam se as diferenças individuais podem ser devidas à hereditariedade e/ ou fatores ambientais (Baker \& Clark, 1990).

Para investigar e separar influências hereditárias e ambientais na personalidade e psicopatologia, Gatz (1990) cita quatro tipos de delineamentos: 1) comparação de gêmeos idênticos (monozigóticos $=\mathrm{MZ}$ ) e fraternos (dizigóticos = DZ); 2) estudo de famílias, que podem envolver várias gerações; 3) comparação de irmãos biológicos e adotivos; e, 4) estudos de gêmeos adotivos, nos quais as similaridades na personalidade entre gêmeos MZ criados separados são diretamente atribuídas aos genes, e similaridades de gêmeos criados juntos comparados aos criados separados indicam a importância de compartilhar um mesmo ambiente de criação.

O uso de gêmeos como sujeitos de pesquisa é um método poderoso para examinar influências genéticas e ambientais nas diferenças individuais de comportamento e características de personalidade (Segal, 1990). Estudos de 
gêmeos também são usados nas investigações de influências hereditárias e ambientais na determinação do temperamento, com delineamentos similares aos utilizados nos estudos de personalidade, ou seja, pesquisas com gêmeos MZ e DZ criados juntos e pesquisas com gêmeos adotados, criados separados (Strelau, 1998).

O estudo de gêmeos MZ e DZ criados juntos é o método mais utilizado e está baseado na hipótese de que: 1) diferenças nas características comportamentais observadas em gêmeos $\mathrm{MZ}$ são devido a efeitos ambientais; 2) a variância nas características comportamentais em gêmeos DZ pode ser atribuída a ambos os efeitos, ambientais e genéticos; 3 ) não existem diferenças de efeitos ambientais entre gêmeos MZ e DZ criados juntos; 4) se as diferenças individuais observadas no comportamento são, em dada extensão, determinadas pela hereditariedade, o coeficiente de correlação intra par de gêmeos MZ pode ser maior se comparado à correlação intra par de gêmeos DZ (Strelau, 1998).

Considerando os traços de temperamento e personalidade, Strelau (1998) afirma que a extroversão e o neuroticismo são os traços mais pesquisados em genética comportamental. Em sua revisão da literatura envolvendo a extroversão, o neuroticismo e outros traços de temperamento investigados por meio de instrumentos como: EASI Temperament Survey; Thurstone Temperament Schedule, Formal Characteristics of Behavior - Temperament Inventory (FCB-TI), Pavlovian Temperament Survey (PTS), Revised Dimensions of Temperament Survey (DOTS- R), Emotionaly - Activity - Sociability Temperament Survey (EAS TS), Eysenck Personality Questionnaire - Revised (EPQ-R), encontrou resultados que indicam a importância da influência exercida pela genética na determinação do traço, sendo que as estimativas variam de acordo com o traço em estudo.

Em Harturp e Lieshout (1995) as pesquisas apresentadas referem-se a estudos de personalidade e temperamento, as quais indicam que as diferenças entre os indivíduos ocorrem devido à combinação de fatores genéticos e ambientais. Estes autores apresentam dados relacionados à influência exercida pela genética e pelo ambiente nos fatores do Big Five, que estão relatados em livro de Loehlin publicado em 1992. Os resultados indicam que os efeitos genéticos aditivos (dosagem genética que considera semelhanças entre pais e filhos, resulta na observação de similaridades, em diferentes graus entre parentes (Goldsmth, Buss \& Lemery, 1997) são responsáveis por $22 \%$ a $46 \%$ na variação individual das amostras estudadas; efeitos não aditivos (resultado da dominância genética e outras interações entre genes, proporcionando maior semelhança entre gêmeos MZ, menor semelhança entre irmãos biológicos e gêmeos DZ, e não semelhança entre pais e descendentes (Goldsmth \& cols., 1997) são responsáveis por $11 \%$ a $19 \%$ (exceto para abertura para experiência, que ocorre entre $2 \%$ e $5 \%$ ); o ambiente familiar compartilhado é responsável por $0 \%$ a $11 \%$; e o restante da variação, $44 \%$ a $55 \%$, representa algumas combinações de efeitos ambientais únicos para o indivíduo, interação genótipo ambiente, ou medidas de erro.

A inserção de dados do Big Five na presente pesquisa decorre do fato de que vários fatores relacionados pelo Big Five (extroversão, agradabilidade, conscienciosidade, estabilidade emocional e cultura) são também relacionados como dimensões ou traços de temperamento. Teóricos do desenvolvimento consideram que as características temperamentais infantis podem ser precursoras dos fatores do Big Five encontrados em adolescentes e adultos (Strelau, 1998; Strelau \& Angleitner, 1991).

Segal (1990), a partir de revisões de diversos estudos, afirma que "pesquisas de personalidade e temperamento envolvendo gêmeos convergem para temas comuns: 1) fatores genéticos influenciam substancialmente os comportamentos, e 2) importante efeitos ambientais são aqueles que não são compartilhados"(p. 616), sendo que a maioria dos estudos em gêmeos sugere que $50 \%$ da variação está associada às influências genéticas, e os 50\% restante estão associados a efeitos ambientais, particularmente aqueles fatores ambientais não compartilhados, únicos para cada indivíduo.

Com relação à determinação da extensão em que cada um dos fatores genes e ambiente contribuem para as diferenças individuais, Strelau (1998) e Cipriani (1996) chamam atenção para o fato de que genes e ambiente podem estabelecer uma relação de interação ou correlação, as quais podem muitas vezes confundir as reais origens das semelhanças e/ou diferenças individuais.

A interação de genes e ambiente pode apresentar padrões de comportamentos não predizíveis, como, por exemplo, gêmeos idênticos predispostos a um traço podem parecer similares em ambientes não estressantes, mas sob estresse podem diferir radicalmente na forma de agir (Cipriani, 1996).

A correlação entre gene e ambiente pode ser classificada em três tipos: 1) correlação genótipo - ambiente passiva, os pais podem ser fonte de influências genéticas e ambientais, indivíduos geneticamente relacionados, são expostas a ambientes que se correlacionam com sua predisposição genética; 2) correlação genótipo - ambiente reativa ocorre quando os pais ou outra pessoa significativa reage ao comportamento geneticamente determinado, fortalecendoo ou enfraquecendo-o; 3) correlação genótipo - ambiente ativa refere-se à situação em que o indivíduo ativamente busca, seleciona ou cria seu próprio ambiente de acordo 
com tendências comportamentais geneticamente determinadas (Cipriani, 1996; Strelau, 1998).

Qual a importância de conhecer a origem biológica do comportamento, mais especificamente do temperamento? A importância reside no fato de que as informações proporcionadas permitem conhecer tendências comportamentais e inclinações individuais hereditárias. Porém é falso afirmar que comportamentos influenciados pela hereditariedade não possam ser modificados, pois embora as pessoas tenham tendências para se comportar em uma determinada direção, psicólogos podem fornecer orientações para o indivíduo criar ou localizar ambientes que possam ser sua "zona de conforto", desafiante, mas não devastadora e estudar alternativas para que ele modifique algum estilo, marcando uma possível adaptação (Gatz, 1990).

Como área de estudo, para Teiglasi (1995) o temperamento, bem como sua avaliação, constitui uma área ativa de pesquisa com aplicabilidade sobre uma variedade de aspectos do desenvolvimento e saúde mental, tais como formação de consciência, interação entre pares, problemas de comportamento, realização escolar, psicopatologia, vulnerabilidade e resistência ao estresse. Para este autor, os extremos temperamentais constituem fatores de risco. Desta forma, dimensões específicas de temperamento podem ser vistas como precursoras de desajustamentos.

Segundo Thomas e Chess (Goldsmith \& cols., 1987), o temperamento deve ser considerado em termos do contexto em que ocorre, como um fator de influência bidirecional. O indivíduo dentro dessa visão é encarado como influenciador ativo de seu ambiente, bem como sujeito a ser influenciado por este (Rutter, 1987). Isto quer dizer que as características temperamentais podem influenciar o tipo de interação que será estabelecida entre o indivíduo e seu ambiente, agindo sobre o comportamento de outras pessoas que se relacionam com ele, e influenciando no desenvolvimento futuro do próprio indivíduo (Lerner 1983; Strelau, 1991).

Chess e Thomas (1991) consideram que um desenvolvimento psicológico normal ou anormal depende tanto do temperamento como da interação entre temperamentos, e outras características do ambiente. Para estes autores, a combinação de demandas do contexto e características individuais é um modelo extremamente útil na prevenção e tratamento de desordens, especialmente quando o indivíduo ainda é criança, pois durante este período do desenvolvimento, aconselhamentos e orientações aos pais podem ser meios efetivos, tanto na prevenção, como no tratamento de problemas psicossociais.

A este respeito Mussen, Conger, Kagan e Huston (1988) escrevem que diferenças ou similaridades no temperamento de pais e filhos não implicam necessariamente em pior ou melhor entrosamento, o importante é a identificação de tais características objetivando uma interação mais eficaz.

De acordo com o exposto acima, é possível constatar a importância da avaliação das características de temperamento, mais especificamente do temperamento infantil, principalmente pelo caráter preventivo da intervenção possível quando a avaliação é feita. Orientando pais, professores e mesmo planejando estratégias de facilitação das relações interpessoais até a adolescência, muitos problemas poderiam ser evitados.

Além da importância do estudo e avaliação do temperamento para o adequado ajustamento do indivíduo ao meio no qual está inserido, pesquisas têm sido conduzidas associando temperamento, resiliência e bem estar subjetivo.

Pesquisas realizadas por Diener (1998), Lu, Shih, Lin e Ju (1997), Costa, McCrae e Norris (1981), Nunes, Silveira, Serra, Anton e Hutz (1999) relatam que a dimensão extroversão está correlacionada positivamente ao bem estar subjetivo, o qual é um importante indicador do ajustamento sócio emocional do indivíduo. Resultados obtidos por Nunes e colaboradores (1999) em uma pesquisa investigando a relação entre bem estar subjetivo e traços de personalidade constatou correlações significativas positivas com o fator extroversão e negativas com o fator neuroticismo/ estabilidade emocional, o que demonstra a importância dos traços de personalidade na determinação do bem estar subjetivo. Diener (1998) nota que o bem estar subjetivo está relacionado ao temperamento herdado, permanecendo estável ao longo do tempo, e consistente entre as situações.

Outro constructo correlacionado com o temperamento é a resiliência. Dimensões de temperamento relacionadas à flexibilidade, capacidade de adaptação do indivíduo, têm apresentado correlações positivas com a resiliência. Losel e Bliesener (1994), em sua pesquisa, obtiveram dados que indicam que os indivíduos resilientes são caracterizados por serem mais inteligentes e mais flexíveis no temperamento, apresentam auto conceito positivo, percebem-se como capazes e orientados para realização, tendem a ser mais ativos. Teóricos como Laucht (1999), Smith e Prior (1995), e Rutter (1993), relacionam características temperamentais como um dos fatores responsáveis pela resiliência.

Informações sobre a correlação que existe entre o temperamento e constructos como bem estar subjetivo e resiliência são extremamente importantes, pois fornecem elementos para a elaboração de programas de prevenção e intervenção. 


\section{Uma Teoria para Avaliação das Características Temperamentais}

Considerando a diversidade de teóricos pesquisando o temperamento, as diferentes definições e delimitações do constructo, e conseqüentemente os inúmeros instrumentos para sua avaliação, foi selecionada para o embasamento teórico do presente trabalho a Teoria Regulativa do Temperamento - RTT desenvolvida por Jan Strelau, que utiliza como um dos instrumentos para a avaliação do temperamento a escala Pavlovian Temperament Survey - PTS. Esta escolha ocorreu devido a ênfase dada por esta teoria à origem biológica do temperamento, aspecto pesquisado no presente trabalho, e também devido ao fato de que a escala Pavlovian Temperament Survey - PTS, ser um instrumento amplamente pesquisado, e utilizado em estudos transculturais em 16 países (idiomas) por mais de 30 pesquisadores: Alemanha, Polônia, Estados Unidos, Austrália, Bélgica, Brasil, Bulgária, Holanda, Grécia, Hungria, Itália, Japão, Coréia, Romênia, Rússia e Espanha (Strelau, Angleitner \& Newberry, 1999). Pouco conhecido nos Estados Unidos, o modelo de Strelau tem influenciado pesquisadores do temperamento na Europa, e tem originado juntamente com o modelo de Eysenck numerosos estudos experimentais (Clark \& Watson, 1999). No Brasil, a escala PTS vem sendo estudada e validada em seu formato para adolescentes e adultos pela equipe do Laboratório de Avaliação e Medidas Psicológicas - LAMP da PUC Campinas (Guzzo, Primi, Pereira \& Valli, 2000; Guzzo, Riello \& Primi, 1996).

Jan Strelau desenvolveu sua teoria baseada nas concepções de funcionamento do sistema nervoso de Pavlov, e em pesquisas e teorias desenvolvidas no período de 1950 e 1960 na Europa Ocidental e nos Estados Unidos, as quais deram origem à Teoria Regulativa do Temperamento - RTT (Strelau, 1998), que tem influenciado o pensamento de pesquisadores do Leste Europeu. A Teoria Regulativa do Temperamento em seus primórdios considerava o temperamento como se referindo a características formais de comportamento, sendo expresso através do nível de energia e fatores temporais do comportamento. O nível de energia era distinguido em reatividade e atividade, os quais eram considerados dois traços básicos de temperamento; já os fatores temporais do temperamento se referiam a velocidade, tempo, persistência, reincidência, regularidade e mobilidade. Revisões nas concepções teóricas da RTT conduziram a sua descrição atual, que é o resultado de quase 40 anos de pesquisa, a qual estabelece que:

O temperamento se refere a traços básicos, relativamente estáveis, expressos principalmente nas características formais de reações e comportamento. Estes traços estão presentes desde cedo na criança e podem ser encontrados em animais. Primariamente determinado por mecanismos de origem biológica, o temperamento está sujeito a mudanças causadas pela maturação e pela interação indivíduo - genótipo específico - ambiente. (Strelau, 1998, p.165)

Nos estudos iniciais e por quase duas décadas, o principal instrumento de medida de dois traços da RT'T (reatividade e mobilidade) foi o Strelau Temperament Inventory (STI), o qual foi posteriormente revisado e publicado sob o título de Strelau Temperament Inventory - Revised (STI-R). Devido a este instrumento avaliar três propriedades clássicas do temperamento pavloviano (força de excitação (FE), força de inibição (FI) e mobilidade (MO)), foi renomeado por Strelau e Angleitner de Pavlovian Temperament Survey (PTS). Para medida das características temporais do comportamento, em algumas ocasiões era utilizado o Temporal Traits Inventory (TTI). Acompanhando os avanços teóricos da Teoria Regulativa do Temperamento, recentemente Strelau e Zawadzki construíram um novo inventário, o Formal Characteristics of Behavior - Temperament Inventory (FCB-TI) (Strelau, 1998).

A avaliação das características de temperamento, nesta perspectiva teórica e utilizando como instrumento a escala Pavlovian Temperament Survey, apresenta resultados referentes a dados coletados em 16 países, envolvendo a participação de 13393 sujeitos de ambos os sexos (masculino $=5018$, feminino $=7042)$ e com idades variando de $10 \mathrm{a}$ 85 anos. Os resultados obtidos indicam que os sujeitos foram caracterizados por pontuações médias mais elevadas no fator $M O(2,68)$ intermediária no fator FI $(2,64)$ e menores no fator FE $(2,48)$. Quando considerado o sexo como variável para avaliação das características de temperamento, foi possível observar que os sujeitos masculinos $(M O=2,69$, $F I=2,66, F E=2,48)$ apresentaram pontuações médias maiores que os femininos $(M O=2,67, F I=2,62, F E=$ $2,35)$. Considerando especificamente a amostra de sujeitos brasileiros $(n=392)$, de ambos os sexos (masculino = 143 , feminino $=249)$ e com idade variando de 10 a 72 anos, que também fazia parte deste estudo, foi possível observar que a distribuição das pontuações médias obtidas nos fatores foi similar, $M O(2,74)$ foi o fator com pontuação média maior, $F I(2,66)$ apresentou pontuação média intermediária e FE $(2,25)$ apresentou a menor pontuação. Quando considerado o sexo da amostra de sujeitos brasileiros, foi possível constatar que também os sujeitos masculinos $(M O=2,76, F I=2,69, F E=2,30)$ apresentaram pontuações mais elevadas que os sujeitos femininos $(M O=2,74, F I=2,64, F E=2,23)($ Strelau \& cols., 1999). 
Em outro estudo desenvolvido por Catini (1999) envolvendo a participação de 72 sujeitos de ambos os sexos, com idades variando de 7 a 13 anos, em uma amostra brasileira, utilizando a escala PTS em sua versão infantil, os resultados obtidos na distribuição das pontuações médias obtidas pelos sujeitos nos fatores apresentou pequena alteração entre FE e FI. O fator MO manteve-se como o fator com pontuação mais elevada, com pontuação intermediária FE e por último FI com pontuação menor. Quando considerado o sexo destes sujeitos, os meninos apresentaram pontuações médias mais elevadas em FE, no entanto as meninas apresentaram pontuações maiores em $M O$, principalmente na faixa etária dos 11 aos 13 anos. Em relação ao fator FI, as pontuações médias obtidas por meninos e meninas foram praticamente iguais. Quanto à idade, sujeitos de 11 a 13 anos apresentaram pontuações maiores do que os de 7 a 10 anos, independente dos fatores.

A diferença na pontuação dos fatores obtidas nestes dois estudos (Catini, 1999; Strelau \& cols., 1999) está prevista na literatura, pois como afirma Strelau e colaboradores existe uma tendência a diminuição da força de excitação e aumento da força de inibição com o passar dos anos, isto ocorre possivelmente devido às influências exercidas pelo meio social.

A interação entre traços de temperamento individuais e "nicho de desenvolvimento" resultam em formas individuais específicas de adaptação. Os traços de temperamento servem a uma função adaptativa particular e diferentes efeitos desenvolvimentais e comportamentais ocorrem dependendo da interação com o ambiente. É importante mencionar também que dependendo da cultura, as características temperamentais podem ser expressas diferentemente em comportamentos culturais específicos (Strelau \& cols., 1999).

Considerando a importância do temperamento para prevenção de problemas psicossociais, e a importância do substrato biológico para definição do constructo, o presente estudo destina-se a investigar o temperamento de crianças de 7 a 14 anos, objetivando verificar características de temperamento predominantes, possíveis diferenças envolvendo as variáveis sexo e faixa etária, bem como verificar a influência exercida pela genética na determinação das características de temperamento.

\section{Método}

\section{Participantes}

Participaram desse estudo 26 pares de gêmeos criados juntos, com idades variando de 7 a 14 anos: 15 pares de gêmeos monozigóticos $(57,7 \%)$ e 11 pares de gêmeos dizigóticos (42,3\%), os quais totalizavam 52 sujeitos, sendo 27 do sexo feminino $(51,9 \%)$ e 25 do sexo masculino (48,1\%), divididos em duas faixas etárias: 34 sujeitos de 7 a $10 \operatorname{anos}(65,4 \%)$ e 18 sujeitos de 11 a $14 \operatorname{anos}(33,6 \%)$. Esta amostra cursava da primeira a oitava série de escolas públicas e particulares de Campinas e região, provenientes de diversas classes sociais.

Participaram como informantes do temperamento dos sujeitos 25 mães $(96,2 \%)$ e um pai $(3,8 \%)$ com idades variando de 25 a 51 anos, possuindo grau de escolarização que variava do não alfabetizado ao superior completo. Dentre estes informantes, 14 dedicavam cuidados integrais aos filhos $(53,9 \%)$, ou seja, interagiam com os filhos durante o dia todo, com exceção do período em que os mesmos encontravam-se na escola; 11 informantes dedicavam cuidados parciais $(42,3 \%)$, interagiam com o filho durante um período do dia, e um informante não especificou o tempo de interação $(3,8 \%)$.

\section{Instrumentos}

Foi utilizada para coleta de dados a escala PTS - Pavlovian Temperament Survey versão infantil, 7 a 14 anos, adaptada para o Brasil por Guzzo, Catini, Pereira e Valli (1999), a partir da versão alemã de Hoogendorp (1992), sendo esta baseada na versão adulta da escala de mesmo nome, desenvolvida por Strelau, Angleitner e Ruch (1990). A Pavlovian Temperament Survey versão infantil, conforme previsto por seu autor, deve ser aplicada na mãe, ou seja, a mãe vai responder aos itens da escala pensando nos comportamentos e atitudes de seu filho avaliado.

A escala Pavlovian Temperament Survey versão infantil, designada no presente trabalho como "PTS infantil", é composta por 252 itens, que avaliam três fatores, baseados nas propriedades pavlovianas do Sistema Nervoso Central: Força de Excitação (FE), Força de Inibição (FI) e Mobilidade (MO), as quais constituem três sub-escalas designadas pelo mesmo nome do fator, que podem ser avaliadas independentemente uma da outra (Strelau \& cols., 1999).

O fator força de excitação (FE) está presente em 90 itens da escala, e representa a capacidade do indivíduo manter-se sem inibição diante de uma situação de estimulação. O fator força de inibição (FI) está incluído em 84 itens, e refere-se a capacidade do indivíduo interromper um determinado comportamento quando necessário, ou efetuar uma mudança de reação. A mobilidade (MO) é definida como a habilidade de responder adequadamente a contínuas mudanças no ambiente, e está presente em 78 itens. 
Os 252 itens da PTS infantil são avaliados pelo formato Likert, com quatro possibilidades de resposta: concordo plenamente, concordo, discordo e discordo plenamente, com a pontuação variando de 1 a 4 pontos.

A escala PTS infantil é composta por um caderno que contém as instruções e os 252 itens, além de uma folha de resposta, que apresenta campos específicos para escrever os dados de identificação do sujeito e do informante (mãe ou pai), e para assinalar a resposta a cada um dos itens da escala.

Estudo preliminar sobre as qualidades psicométricas da escala PTS infantil (Catini, 1999), obteve resultados favoráveis no que diz respeito à consistência interna dos fatores avaliados $(F E=0,90 ; F I=0,92 ; M O=0,89)$ calculada pelo alpha de Cronbach. No que diz respeito à validade do instrumento, correlações obtidas pelos mesmos sujeitos na versão adulta da escala (em fase de normatização por Guzzo \& cols., 2000) e a versão infantil apresentaram-se favoráveis à validade da PTS infantil.

\section{Procedimentos}

Os pares de gêmeos utilizados como sujeitos no presente trabalho foram localizados por meio de contato pessoal e apresentação de uma carta, contendo a identificação, a filiação institucional da pesquisadora e os objetivos do estudo, junto à direção de escolas estaduais e particulares, as quais verificavam a presença de gêmeos matriculados na instituição e forneciam, mediante a concordância dos pais, um telefone ou endereço para contato.

Estabelecido o contato, os pais eram informados sobre o objetivo do estudo, e era verificada a disponibilidade preferencialmente da mãe em participar da pesquisa; na ausência desta, era verificada a possibilidade do pai colaborar. Em caso afirmativo, eram então marcados um local e horário para a coleta de dados.

A coleta de dados era iniciada a partir da anuência dos pais e a mesma foi realizada por meio de entrevista individual, na qual a mãe ou pai dos gêmeos, respondia aos itens da escala. Além de responder aos itens da escala, a mãe ou pai recebia informações sobre o que é o temperamento, o objetivo da pesquisa e seu caráter sigiloso.

\section{Resultados}

Num primeiro momento, antes da apresentação dos resultados referentes às características temperamentais $\mathrm{e}$ a influência exercida pela genética na determinação do temperamento, faz-se importante apresentar os dados sobre as qualidades psicométricas da escala PTS infantil. Resultados obtidos por meio do cálculo do coeficiente alpha de Cronbach (Adánez, 1999; Pasquali, 1997) evidenciaram índices de consistência interna bastante satisfatórios nos três fatores avaliados pelo instrumento: $F E=0,86 ; \quad F I=0,81 ; \quad M O=0,85(F E=$ força de excitação, $F I=$ força de inibição, $M O=$ mobilidade).

Definido o índice de precisão, a seguir serão apresentados os resultados referentes à caracterização do temperamento dos sujeitos, considerando-se as variáveis independentes: sexo e faixa etária.

O primeiro passo para análise desses resultados consistiu na somatória dos pontos obtidos pelos sujeitos em cada um dos fatores. Considerando-se que os fatores avaliados pela PTS infantil apresentavam números diferentes de itens $(F E=90, F I=84$ e $M O=78)$, foi realizada a transformação destes resultados brutos para a amplitude padrão da escala, com a escala Likert variando de 1 a 4 pontos em todos os 252 itens da escala. Para tal, foi considerada a somatória dos pontos em cada fator dividida pelo número de itens, sendo em seguida calculada a média obtida pelo grupo. Esta média variava de acordo com as variáveis independentes consideradas.

Os resultados obtidos por meio do cálculo da pontuação média nos fatores (Tabela 1) demonstraram que o fator que obteve média mais elevada foi $\mathrm{MO}$, aparecendo em seguida FE e por último, com pontuação

Tabela 1

Pontuação Média Obtida nos Fatores da PTS Infantil Considerando-se o Grupo Total de Sujeitos, e as Variáveis Sexo e Faixa Etária

\begin{tabular}{|c|c|c|c|c|c|c|c|c|c|c|}
\hline \multirow[t]{3}{*}{ Fatores } & \multicolumn{2}{|c|}{ Total sujeitos $(n=52)$} & \multicolumn{4}{|c|}{ Sexo } & \multicolumn{4}{|c|}{ Faixa etária } \\
\hline & \multirow[b]{2}{*}{$m$} & \multirow[b]{2}{*}{$d p$} & \multicolumn{2}{|c|}{$\begin{array}{l}\text { Feminino } \\
(n=27)\end{array}$} & \multicolumn{2}{|c|}{$\begin{array}{l}\text { Masculino } \\
(n=25)\end{array}$} & \multicolumn{2}{|c|}{$\begin{array}{c}7 \text { a } 10 \text { anos } \\
(n=34)\end{array}$} & \multicolumn{2}{|c|}{$\begin{array}{c}11 \text { a } 14 \text { anos } \\
(n=18)\end{array}$} \\
\hline & & & $m$ & $d p$ & $m$ & $d p$ & $m$ & $d p$ & $m$ & $d p$ \\
\hline$\overline{\mathrm{FE}}$ & 2,53 & 0,16 & 2,54 & 0,16 & 2,51 & 0,15 & 2,48 & 0,16 & 2,61 & 0,12 \\
\hline FI & 2,43 & 0,15 & 2,45 & 0,17 & 2,41 & 0,12 & 2,43 & 0,15 & 2,44 & 0,15 \\
\hline $\mathrm{MO}$ & 2,72 & 0,15 & 2,78 & 0,13 & 2,66 & 0,15 & 2,70 & 0,14 & 2,76 & 0,16 \\
\hline
\end{tabular}


mais baixa FI. Esta distribuição das médias obtidas nos fatores $(M O>F E>F I)$ manteve-se constante, independente da variável considerada (sexo e faixa etária).

No que se refere à comparação das médias obtidas nos fatores por sujeitos femininos e masculinos (Tabela 1), notou-se que os sujeitos femininos $(F E=2,54 ; F I=$ $2,45 ; M O=2,78)$ apresentaram médias mais elevadas que os sujeitos masculinos ( $F E=2,51 ; F I=2,41 ; M O=2,66$ ).

Quando considerada a faixa etária (Tabela 1), os dados obtidos demonstraram que os sujeitos de 11 a 14 anos obtiveram médias mais elevadas $(M O=2,76 ; \mathrm{FE}=2,61$; $F I=2,44)$ do que os sujeitos de 7 a 10 anos $(M O=2,70$; $F E=2,48 ; F I=2,43)$.

Para verificar a variância das médias obtidas nos fatores, considerando-se às variáveis faixa etária e sexo, foi realizada a MANOVA (Aron \& Aron, 1999): 2x2x3, envolvendo dois sexos (masculino e feminino), duas faixas etárias (7 a 10 e 11 a 14 anos) e três fatores (FE, FI, MO). Os resultados desta análise são apresentados na Tabela 2.

De acordo com os dados desta tabela, notou-se uma diferença significante nas pontuações médias obtidas, envolvendo a variável faixa etária $(F=3,75 ; p=0,017)$ e a variável sexo $(F=3,38 ; p=0,026)$. Para identificar entre sujeitos qual variável dependente (FE, FI, MO) sofre o efeito das variáveis sexo e faixa etária, foram realizadas análises univariadas (Tabela 3), por meio das quais percebeu-se que no que se refere à variável faixa etária, os fatores que contribuíram para uma variação significativa entre os sujeitos foram $\mathrm{FE}$, onde $F(1,48)=$ 10,$35 ; p=0,002$ e MO, onde $F(1,48)=5,56 ; p=0,022$. Quanto à variável sexo, o fator que contribuiu para variação significativa também foi $\mathrm{MO}$, onde $F(1,48)=$ $10,38, p=0,002$.

Para verificar a influência exercida pela genética na determinação do temperamento, foi calculada a correlação de Pearson (Aron \& Aron, 1999), considerando os resultados obtidos intra e entre pares de gêmeos nos três fatores avaliados pela PTS infantil. Dado o fato de que gêmeos monozigóticos (MZ) e dizigóticos (DZ) formavam grupos com números diferentes de sujeitos, foi calculada, a partir da correlação de Pearson a correlação ajustada - raju (Howell, 1997), que se destina a equiparar grupos com diferentes números de sujeitos.

Os dados obtidos na correlação ajustada (Tabela 4), indicaram que entre gêmeos MZ todos os fatores apresentaram correlações significativas e elevadas, porém com diferentes índices. $\mathrm{O}$ fator MO foi o que apresentou índice de correlação ajustada mais elevada $(0,858)$,

Tabela 2

Resultados da Análise de Variância Investigando o Efeito Sexo, Faixa Etária e Fatores da PTS Infantil

\begin{tabular}{|c|c|c|c|c|c|}
\hline \multirow[t]{2}{*}{ Efeito } & \multicolumn{2}{|c|}{$g l$} & \multirow[t]{2}{*}{ T } & \multirow[t]{2}{*}{$F$} & \multirow[t]{2}{*}{$p$} \\
\hline & entre & intra & & & \\
\hline Sexo & 3 & 46 & 0,819 & $3,38^{*}$ & 0,026 \\
\hline Faixa etária & 3 & 46 & 0,803 & $3,75^{*}$ & 0,017 \\
\hline Sexo x faixa etária & 3 & 46 & 0,967 & 0,52 & 0,665 \\
\hline
\end{tabular}

Nota: $*$ Diferença significativa entre e inter sujeitos

Tabela 3

Análise dos Fatores que Contribuíram para Variação Significativa nas Variáveis Sexo e Faixa Etária

\begin{tabular}{lccl}
\hline Variável independente & Variável dependente & $F$ & $p$ \\
\hline Faixa etária & FE & $10,35^{*}$ & 0,002 \\
& FI & 0,096 & 0,758 \\
\multirow{4}{*}{ Sexo } & MO & $5,56^{*}$ & 0,022 \\
& FE & 1,18 & 0,82 \\
& FI & 0,33 & 0,565 \\
& MO & $10,38^{*}$ & 0,002 \\
\hline
\end{tabular}

Nota: $*$ Diferença significativa entre e inter sujeitos 
Tabela 4

Correlação no Temperamento de Gêmeos Monozigóticos e Diحigóticos

\begin{tabular}{lcccccc}
\hline Tipo de gêmeo & \multicolumn{2}{c}{ FE } & \multicolumn{2}{c}{ FI } & \multicolumn{2}{c}{$\mathrm{MO}$} \\
\hline Monozigóticos & $0,699^{* *}$ & $0,670^{* *}$ & $0,702^{* *}$ & $0,673^{* *}$ & $0,869^{* *}$ & $0,858^{* *}$ \\
Dizigóticos & $0,834^{* *}$ & $0,813^{* *}$ & $0,885^{* *}$ & $0,871^{* *}$ & 0,283 & $-0,148$
\end{tabular}

Nota: ${ }^{* *}$ Correlação significativa ao nível 0,01

intermediado por FI $(0,673)$ e por último FE $(0,670)$. Entre gêmeos DZ, somente FE e FI apresentaram correlações ajustadas significativas e elevadas $(F I=0,871$; $F E=0,813)$, no fator MO a correlação ajustada obtida foi negativa $(-0,148)$.

Quando comparados gêmeos MZ e DZ, verificandose qual possuía correlações ajustadas mais significantes, notou-se que a correlação ajustada mais alta foi a dos gêmeos DZ no fator FI $(0,871)$, aparecendo em seguida gêmeos $\mathrm{MZ}$ no fator $\mathrm{MO}(0,858)$, gêmeos $\mathrm{DZ}$ no fator FE $(0,813)$, e finalmente gêmeos MZ nos fatores FI $(0,673)$ e FE $(0,670)$.

\section{Discussão}

A escala PTS infantil apresentou neste estudo índices de consistência interna satisfatórios $(F E=0,86 ; F I=0,81$; $M O=0,85)$. Quando comparados estes resultados com os obtidos por Catini (1999) em estudo anterior envolvendo a PTS infantil $(F E=0,90 ; F I=0,92 ; M O=$ 0,89), é possível perceber que os índices obtidos nesta pesquisa são um pouco menores. Considerando-se que, em ambos os estudos, os índices obtidos apresentaramse satisfatórios, e sendo pequena a diferença entre os resultados nos dois estudos, é possível afirmar que o instrumento apresentou indicadores de consistência interna que instigam e permitem a continuidade dos estudos.

No que diz respeito às características de temperamento avaliadas pela PTS infantil, os resultados obtidos indicaram que esta amostra de sujeitos apresentou como característica marcante, segundo avaliação das mães, o fator mobilidade, ou seja, são indivíduos que apresentam habilidade de responder tão adequadamente quanto necessário a contínuas mudanças no ambiente. Em seguida, apareceu a força de excitação, que se manifesta na habilidade do indivíduo de resistir a uma estimulação intensa e prolongada sem manifestar inibição. Como característica menos presente neste grupo de sujeitos, apareceu a força de inibição, a qual se refere à capacidade do indivíduo de interromper um determinado comportamento quando necessário, ou efetuar uma mudança de reação. É importante mencionar que esta caracterização de temperamento permaneceu constante independente da variável considerada (sexo e faixa etária)

Comparando-se estes resultados aos dados obtidos na literatura, por meio da PTS adulto, em avaliações de adolescentes e adultos (Riello, 1999; Strelau \& cols., 1999), verificou-se algumas diferenças: é esperada uma pontuação mais elevada em MO, intermediária em FI e menor em FE. O que faz com que a hierarquia dos fatores seja diferente em FE e FI? Uma hipótese a ser levantada é a da influência cultural interferindo nas características de temperamento dos sujeitos, pois tal como previsto na literatura (Strelau \& col., 1999), a interação entre os traços de temperamento do indivíduo e o ambiente resulta em diferentes formas de adaptação e diferentes valores nas disposições temperamentais da criança. Não seria a variável idade um fator importante para a hierarquia diferenciada dos fatores? Strelau e colaboradores (1999) afirmam que sujeitos mais velhos apresentam pontuações mais elevadas em FI e menores em FE quando comparados a sujeitos mais jovens, isto possivelmente devido às influências exercidas pelo meio social. Neste momento é importante lembrar que os sujeitos envolvidos neste estudo são mais novos dos que o da literatura citada acima, e quando comparados aos resultados obtidos por Catini (1999), com sujeitos da mesma faixa etária, a distribuição das pontuações médias obtidas nos fatores são similares.

A análise das características temperamentais, quando considerada a variável sexo, evidenciou que os sujeitos femininos apresentaram pontuações mais elevadas que os masculinos nos três fatores (MO, FE, FI), sendo que esta diferença se mostrou mais significante no fator MO, o que caracteriza as meninas como possuindo maior facilidade em responder adequadamente às mudanças do ambiente. A maior presença do fator $\mathrm{MO}$ em meninas também foi obtido por Catini (1999), utilizando a mesma escala (PTS infantil) em sujeitos da mesma faixa etária (7 a 14 anos).

A caracterização do temperamento da amostra considerando sujeitos mais novos e mais velhos demonstrou que os sujeitos da faixa etária de 11 a 14 anos apresentaram 
pontuações mais elevadas do que os sujeitos de 7 a 10 anos, sendo que esta diferença se mostrou significativa nos fatores FE e MO. Tal dado demonstrou que os sujeitos de 11 a 14 anos são caracterizados como possuindo maior facilidade para responder adequadamente às mudanças do ambiente, não apresentando inibição diante de uma estimulação intensa. Dados similares a estes foram obtidos por Catini (1999).

No que se refere à comparação das correlações observadas nas características de temperamento de gêmeos MZ e DZ, constatou-se que gêmeos MZ apresentavam correlações significativas e elevadas nos três fatores avaliados, e gêmeos DZ em dois fatores. Dados da literatura pesquisada indicam que o estudo de crianças gêmeas tem consistentemente sugerido moderada influência genética na maioria das dimensões de temperamento, sendo esperado que gêmeos MZ, que compartilham 100\% de genes, obtenham correlações altas, enquanto que gêmeos DZ, que compartilham em média 50\% dos genes, obtenham correlações mais baixas, menores do que a metade da correlação de gêmeos MZ (Saudino, McGuire, Hetherington, Reiss \& Plomin, 1995; Segal, 1990; Strelau, 1998). Em seu artigo, Goldsmith, Buss e Lemery (1997) mencionam que em pesquisas baseadas nos relatos dos pais, geralmente são encontradas evidências da influência genética com correlações em gêmeos $\mathrm{MZ}$ variando de 0,50 a 0,80 , e de gêmeos $\mathrm{DZ}$ variando de 0 a 0,50 .

Comparando-se os dados da literatura com as correlações encontradas entre os gêmeos neste estudo, e lembrando que os mesmos tiveram suas características de temperamento avaliadas pelos pais, é possível reconhecer a influência genética como um fator importante na determinação das três dimensões de temperamento avaliadas pela PTS infantil, principalmente quando considerados as correlações significativas e elevadas obtidas pelos gêmeos MZ.

Através de uma análise mais detalhada dos dados, foi possível perceber que os fatores FE e FI apresentavam correlações significativas e altas tanto em gêmeos MZ quanto em gêmeos DZ. Porém, um aspecto que chamou a atenção foi que as correlações destes fatores se mostraram mais elevadas em gêmeos DZ. Não seriam esperadas correlações mais elevadas em gêmeos MZ, de acordo com a literatura? $\mathrm{O}$ que estaria influenciando tais correlações? Um aspecto a ser levado em consideração neste momento se relaciona com o fato do temperamento dos gêmeos ter sido avaliado pela mãe ou pai, ou seja, o mesmo reflete a percepção que os pais têm sobre as características de temperamento de seus filhos.

Um outro aspecto poderia ser de que os pais, diante da apresentação dos objetivos do presente estudo, possam ter sido influenciados por este, levando principalmente os pais de gêmeos DZ a "exagerarem" às similaridades dos filhos gêmeos.

Outra hipótese, mencionada na literatura (Cipriani, 1996; Strelau, 1998), que pode ser levada em consideração para tentar explicar correlações mais elevadas nos fatores FE e FI nos gêmeos DZ, se refere à influência exercida pelos pais no temperamento dos filhos. Não estariam os pais de gêmeos DZ reagindo aos comportamentos dos filhos e proporcionando ambientes que favorecessem uma maior similaridade na manifestação do temperamento deles? Os pais de gêmeos $\mathrm{MZ}$, ao contrário, não poderiam estar proporcionando ambientes que favorecessem e estimulassem a diferença na manifestação das características temperamentais dos filhos? De acordo com dados fornecidos pelos informantes, os gêmeos foram criados juntos, porém não foram feitos questionamentos sobre como era a atitude dos pais para com cada um dos filhos. Há a necessidade de maiores informações dos informantes para checar esta hipótese.

É importante mencionar que dados obtidos na literatura atestam que o temperamento pode sofrer influências de fatores do contexto (Goldsmith \& Rieser-Danner, 1986; Goldsmith \& cols. 1987; Strelau, 1998). Considerando a influência do contexto e a expectativa de encontrar índices menores de correlações entre gêmeos $\mathrm{DZ}$, não poderia o ambiente estar influenciando o temperamento destes sujeitos, fazendo com que os mesmos manifestem características similares no que diz respeito aos fatores FE e FI?

Pesquisas em genética comportamental investigam influências de fatores genéticos e ambientais (Plomin \& Rende, 1991), sendo que dependendo do delineamento utilizado fica mais fácil identificar a fonte de influência (Gatz, 1990). Considerando que o presente estudo envolveu somente a participação de gêmeos MZ e DZ criados juntos não é possível afirmar com precisão se seria o ambiente o fator responsável pelos índices elevados e significativos observados nos fatores FE e FI em gêmeos DZ.

No que se refere especificamente à correlação observada no fator MO, foi possível perceber que esta era significativa e elevada em gêmeos $M Z$, o que não ocorria entre gêmeos DZ. Tal dado está plenamente de acordo com o esperado pela literatura (Goldsmith \& cols., 1997; Saudino \& cols., 1995; Segal, 1990), a qual conforme citado anteriormente espera que gêmeos MZ obtenham correlações altas, enquanto que os gêmeos DZ obtenham correlações mais baixas.

De um modo geral, os índices de correlações significativos e elevados observados entre os gêmeos nos 
três fatores (FE, FI, MO) apoiam a influência exercida pelos genes na determinação do temperamento, mas especificamente nos fatores FE e FI fica a dúvida se não seria o ambiente o responsável pelas correlações elevadas e significativas obtidas.

\section{Considerações Finais}

Resultados obtidos neste estudo permitem afirmar que apesar da escala PTS infantil não estar validada para a realidade brasileira, os índices de precisão obtidos foram bastante satisfatórios, e sua aplicação apresentou dados muito interessantes para estudo do constructo e caracterização da amostra.

A análise das características de temperamento desta amostra de crianças e adolescentes, avaliadas pelos pais por meio deste instrumento, indicou como característica predominante deste grupo de sujeitos a mobilidade (MO), independente de qual seja a variável considerada (sexo, faixa etária). Além de representar a característica predominante desta amostra, foi o fator $\mathrm{MO}$ o responsável pela diferença significativa observada nas características de temperamento entre os grupos, quando consideradas as variáveis sexo e faixa etária.

O segundo fator que apareceu caracterizando os sujeitos desta amostra foi a força de excitação (FE), que juntamente com MO, contribuiu para diferenciar os sujeitos mais novos e mais velhos. Já a força de inibição (FI), foi o fator menos presente e não contribuiu para diferenciação dos sujeitos nesta amostra.

Considerados estes dados, foi possível perceber a importância dos fatores MO e FE para caracterização e diferenciação dos sujeitos. Na literatura (Strelau, 1986; Strelau \& cols., 1999; Strelau, 1986) estes fatores têm sido correlacionados significativamente com a extroversão, a qual tem sido vinculada ao bem estar subjetivo (Costa \& cols., 1981; Diener, 1998; Lu \& cols., 1997; Nunes \& cols., 1999). Dimensões temperamentais também têm sido correlacionadas a resiliência (Laucht, 1999); Losel \& Bliesener 1994; Rutter, 1993; Smith \& Prior 1995). Tanto o bem estar subjetivo quanto a resiliência são constructos considerados importantes para o desenvolvimento e ajustamento sócio emocional, bem como auxiliam na identificação de fatores protetivos do indivíduo.

No que se refere à determinação genética do temperamento foi possível perceber que o fator $\mathrm{MO}$ foi o que suscitou maiores evidencias da influência exercida pela genética na determinação do temperamento. Quanto aos fatores FE e FI são encontradas também evidências da influência da genética, mas fica a dúvida se estes não seriam fatores que poderiam estar recebendo forte influência do ambiente na sua manifestação. Para esclarecer qual o fator ou fatores responsáveis, e em que grau o ambiente e a genética influenciam as características temperamentais seriam necessários a realização de novos estudos envolvendo gêmeos $\mathrm{MZ}$ e DZ criados juntos e separados, estudos de familias com filhos adotivos e estudos envolvendo várias gerações de uma mesma família.

Um último ponto aspecto a ser lembrado é o de que estes resultados refletem a percepção que os pais têm sobre seus filhos. Eles são característicos para esta amostra de sujeitos, sendo necessária a realização de novos estudos, para comprovar a generalização dos resultados.

\section{Referências}

Baker, L.A. \& Clark, R. (1990). Introduction to special feature. Genetic origins of behavior: Implications for counselors. Journal of Counseling \& Development, 68(6), 597-600.

Bates, J.E. (1989). Concepts and measures of temperament. Em G.A. Kohnstamm, J.E. Bates \& M.K. Rothbart (Orgs.), Temperament in childhood (pp.3-26). Chichester: Wiley.

Boeree, C.G. (1998). Hans Eysenck and other temperament theorists. [On line] http://www.ship.edu/ cgboeree/eysenck.html.

Buss, A.H. (1995). Personality: Temperament, social behavior, and the self. Massachusets: Allyn and Bacon.

Catini, N. (1999). Temperamento: Estudo inicial da escala PTS infantil. Dissertação de Mestrado não-publicada, Curso de Pós Graduação, Pontifícia Universidade Católica de Campinas. Campinas, São Paulo.

Chess, S. \& Thomas, A. (Orgs.)(1987). Annual progress in child psychiatry and child development. New York: Brunner/Mazel.

Chess, S. \& Thomas, A. (1991). Temperament and the concept of goodness of fit. Em J. Strelau, \& A. Angleitner (Orgs.), Explorations in temperament (pp. 15-28). New York: Plenum Press.

Cipriani, D.C. ( 1996). Stability and change in personality across the life span: Behavioral: Genetic versus evolutionary approaches. Genetic, Social, and General Psychology Monographs, 122(1), 55-74.

Clark, L.A. \& Watson, D. (1999). Temperament: A new paradigm for trait psychology. Em L.A. Pervin, \& O.P. John (Orgs.), Handbook of personality: Theory and research (pp. 399-423). New York: Guilford.

Costa, P.T., McCrae, R.R. \& Norris, A.H. (1981). Personal adjustment to aging: Longitudinal prediction from neuroticism and extraversion. Journals of Gerontology, 36(1), 78-85.

Diener, E. (1998). Subjective well being and personality. Em D. F. Barone, M. Hersen \& colaboradores (Orgs.), Advanced personality. The Plenum series in social/clinical psychology (pp. 311 - 334). New York: Plenum Press.

Gatz, M. (1990). Interpreting behavioral genetic results: Suggestions for counselors and clients. Journal of Counseling \& Development, 68(6), 601605.

Goldsmith, H.H., Buss, K.A. \& Lemery, K.S. (1997). Toddler and childhood temperament: Expanded content, stronger genetic evidence, new evidence for the importance of enviroment. Developmental Psychology, 33 (6), 891-905.

Goldsmith, H.H., Buss, A.H., Plomin, R., Rothbart, M.K., Chess, S. Thomas, A., Hinde, R.A. \& Mccall, R.B. (1987). Rounddtable: What is temperament? Four approaches. Child Development, 58, 505-529.

Goldsmith, H.H. \& Rieser-Danner, L.A. (1986). Variation among temperament theories and validation studies of temperament assessment. Em G.A. Kohnstamm (Org.), Temperament discussed - temperament and development in infancy and childhood (pp. 1-10). Lisse: Swets \& Zeitlinger. 
Guzzo, R.S.L., Primi, R., Pereira, P.C. \& Valli, C.M.M. (2000). Características psicométricas da PTS - versão adulto: Validade, precisão e padronização para a realidade brasileira. Manuscrito submetido à publicação.

Guzzo, R.S.L., Riello, I.C. \& Primi, R. (1996). Pavlovian Temperament Survey - PTS: Análise de itens e teste de realidade. Psicologia Escolar e Educacional, 1 (1), 53-59.

Hoogendorp, N. (1992). Temperament bei kindern: Die entwicklung und überprünfung einer kinderform des PTS (Temperamento de crianças: o desenvolvimento e avaliação de uma versão infantil da PTS). Diplomarbeit im Fakultät für psychologie und Sportwissenschaft na Der Universität Bielefeld.

Ito, P.C.P. \& Guzzo, R.S.L. (2002). Diferenças individuais: Temperamento e personalidade. Estudos de Psicologia, 19(1), 91-100.

Laucht, M. (1999, Outubro). Vulnerability and resilience in the development of children at risk: The role of early mother-child interaction. Conferência apresentada na XXIX Reunião Anual de Psicologia, Campinas, SP.

Lerner, J.V. (1983). The role of temperament in psychosocial adaptation in early adolescents: A test of a "Goodness-of-fit" model. Journal of Genetic Psychology, 143, 149-157.

Losel, F. \& Bliesener, T. (1994). Some high-risk adolescents do not develop conduct problems: A study of protective factors. International Journal of Behavioral Development, 17(4), 753 - 777.

Lu, L., Shih, J.B., Lin, Y.Y. \& Ju, L.S. (1997). Personal and environmental correlates of happiness. Personality Individual Differences, 23(3), 453 - 462.

Mussen, P.H., Conger, J.J., Kagan, J. \& Huston, A.C. (1988). Desenvolvimento e personalidade da criança. São Paulo: Harbra.

Nunes, C.H.S.S., Silveira, A. D., Serra, J.G., Anton, M.C. \& Hutz, C.S. (1999, maio). Relações entre bem-estar subjetivo e características de personalidade. Pôster apresentado no VIII Congresso Nacional de Avaliação Psicológica, Porto Alegre, RS.

Plomin, R. \& Rende, R. (1991). Human behavioral genetics. Annual Review of Psychology, 42, 161-190.

Revelle, W. (1995). Personality process. Annual Review of Psychology, 46, 295 328.

Riello, I.C. (1999). Temperamento: Perfil de adolescentes com diferentes competências em natação. Tese de Doutorado não-publicada, Curso de Pós-Graduação, Pontifícia Universidade Católica de Campinas. Campinas, São Paulo.

Rothbart, M.K. (1986a). A psychobiological approach to the study of temperament. Em G.A. Kohnstamm (Org.), Temperament discussed: Temperament and development in infancy and childhood (pp. 63-72). Lisse: Swets \& Zeitlinger.

Rothbarth, M.K. (1986b). Longitudinal observation of infant temperament. Developmental Psychology, 22(3), 356-365.

Rutter, M. (1987). Temperament, personality and personality disorder. British Journal of Psychiatry, 150, 443-458.
Rutter, M. (1993). Resilience: Some conceptual considerations. Journal of Adolescent Health, 14(8), 626-631.

Saudino, K.J., McGuire, S., Hetherington, E.M., Reiss, D. \& Plomin, R. (1995). Parent ratings of EAS temperaments in twins, full siblings, half siblings, and step siblings. Journal of Personality and Social Psychology, 68(4), 723-733.

Segal, N.L. (1990). The importance of twin studies for individual differences research. Journal of Counseling \& Development, 68(6), 612-622.

Smith, J. \& Prior M. (1995). Temperament and stress resilience in schoolage children: A within-families study. Journal of the American Academy of Child and Adolescent Psychiatry, 34(2), 168 - 179.

Strelau, J. (1986). Pavlovian properties of the nervous system in connection to extraversion-introversion. Psychologische Beiträge, 28, 192 - 205.

Strelau, J. (1991, julho-agosto). Temperament and giftedness in children and adolescents. Trabalho apresentado na "Nineth World Conference on Gifted and Talented Children", Hage Netherlands.

Strelau, J. (1994). The concepts of arousal and arousability as used in temperament Studies. Em J.E. Bates \& T.D. Wachs, (Orgs.), Temperament individual differences at the interface of biology and behavior (pp. 117-141). Washington: American Psychological Association.

Strelau, J. (1997). The contribution of Pavlov's typology of CNS properties to personality research. European Psychologist, 2(2), 125-138.

Strelau, J. (1998). Temperament: A psychological perspective. New York: Plenum.

Strelau, J. \& Angleitner, A. (1991). Temperament research: Some divergences and similarities. Em J. Strelau, \& A. Angleitner (Orgs.), Explorations in temperament: International perspective on theory and measurement (pp. 1-12). New York: Plenum.

Strelau, J., Angleitner, A. \& Newberry, B.H (1999). The Pavlovian Temperament Survey (PTS): An International Handbook. Seattle: Hogrefe \& Huber Publishers.

Strelau, J., Angleitner, A. \& Ruch, W. (1990). The Strelau Temperament Inventory - Revised (STI - R): Theorical consideration and scale development. European Journal of Personality, 4, 209-235.

Teiglasi, H. (1995). Assessment of temperament. Eric Digest [on line] http:// www.ed.gov/databases/eric-digest/ed389963.html.

Windle, M. \& Lerner, R.M. (1984). The role of temperament in dating relationships among young adults. Merril - Palmer Quarterly, 30(2), 163 175 .

\section{Sobre as autoras}

Patrícia do Carmo Pereira Ito é Mestre em Psicologia Escolar e Doutoranda em Psicologia pela PUC - Campinas. Integrante do Laboratório de Avaliação e Medidas Psicológicas - LAMP. Bolsista FAPESP.

Raquel Souza Lobo Guzzo é Professora Titular do Instituto de Psicologia da PUC-Campinas. Doutora em Psicologia Escolar pela Universidade de São Paulo. Coordenadora do Laboratório de Avaliação e Medidas Psicológicas - LAMP. Pesquisadora do CNPq. 